\title{
Preferência pela Liquidez, Racionamento de Crédito e Concentração Bancária Uma Nova Teoria Pós-keynesiana da Firma Bancária
}

José Luís Oreiro
Doutor em Economia (IE/UFRJ), Professor Adjunto do Departamento de Economia da Universidade Federal do Paraná e Bolsista do CNPQ

\section{RESUMO}

O presente artigo tem por objetivo apresentar um modelo geral de firma bancária que incorpore a teoria pós-keynesiana da preferência pela liquidez dos bancos, a hipótese StiglitzWeiss de que a taxa de inadimplência dos devedores é uma função crescente da taxa de juros e a hipótese tobiniana de que a proporção dos depósitos que o banco consegue reter é uma função crescente do grau de concentração do setor bancário. Esse modelo geral nos permite obter três conclusões importantes. Em primeiro lugar, demonstra-se que o spread bancário ótimo é uma função crescente do grau de concentração do setor bancário. Em segundo lugar, demonstra-se que um aumento da taxa básica de juros irá resultar (i) numa redução do spread bancário ótimo e (ii) numa redução do volume de crédito ofertado pelo banco. Por fim, demonstra-se que um aumento do grau de concentração tem um efeito ambíguo sobre a oferta de crédito bancário.

\section{PALAVRAS-CHAVE}

bancos, fragilidade financeira, estrutura de mercado

ABSTRACT

The objective of the present article is to present a general model of the banking firm behavior which encompasses the post Keynesian theory of bank's liquidity preference, the StiglitzWeiss's hypothesis that expected default rate is an increasing function of loan interest rate and the Tobinisque hypothesis that the deposit retention coefficient is an increasing function of the concentration ratio in banking industry. This general model allows us to arrive at some interesting conclusions. First of all, we show that the optimal banking spread is an increasing function of the concentration ratio in banking industry. Second, we show that an increase in the level of the interest rate controlled by the Central Bank will (i) reduce the optimal level of the banking spread, and (ii) will reduce de supply of banking credit. Last, but not least, we show that an increase in the concentration ratio in banking industry has an ambiguous effect over the supply of banking credit.

KEY WORDS banks, financial fragility, market structure

JEL Classification

EI2, E43, E5 I 


\section{INTRODUÇÃO}

A teoria ortodoxa da firma bancária, tal como apresentada, por exemplo, nos escritos de Tobin (1998), considera que o problema decisório fundamental enfrentado pelo banco enquanto firma consiste na escolha entre um conjunto de ativos rentáveis e com baixa liquidez (empréstimos e investimentos) e um outro conjunto de ativos com baixa rentabilidade e alta liquidez (ativos defensivos). ${ }^{1}$

A demanda por ativos líquidos, mas pouco rentáveis, se justifica, no contexto da teoria ortodoxa, pelo fato de que o volume total de depósitos a vista é uma variável aleatória, de tal forma que o banco está sujeito ao risco de ocorrência de uma redução súbita e inesperada do volume dos depósitos em consideração. Embora o banco possa sempre recorrer ao mercado interbancário ou ao redesconto do banco central para obter a liquidez necessária para atender aos saques de seus correntistas, tais operações envolvem, necessariamente, um custo para o banco, seja na forma de juros pagos sobre os empréstimos feitos nos demais bancos ou no banco central ou ainda a perda de reputação ou de prestígio com seus clientes (cf. TOBIN, 1998, p. 182). Nesse contexto, o banco estará disposto a manter ativos pouco rentáveis em carteira como precaução contra a possibilidade de ter que recorrer ao mercado interbancário ou ao redesconto do banco central.

Para pós-keynesianos, a teoria ortodoxa da firma bancária é um arcabouço teórico insatisfatório para a análise do comportamento dos bancos porque, por um lado, desconsidera o fato de que os diferentes ativos possuem diferentes graus de liquidez. Dessa forma, o problema decisório do banco não pode ser apresentado como simplesmente uma escolha entre ativos líquidos e ilíquidos, mas entre graus de liquidez associados aos diversos ativos que o banco pode manter em carteira (cf. CARVALHO, 1998, p. 10).

1 Deve-se ressaltar que na teoria ortodoxa os ativos defensivos não são constituídos apenas por reservas em papel-moeda (voluntárias ou requeridas), mas também depósitos em outros bancos, empréstimos no mercado interbancário e obrigações do Tesouro. Nas palavras de TOBIN: "Defensive assets are (...) assets of very high liquidity. The bank knows that they can be sold, or borrowed against without loss or delay. Defensive assets include currency, deposits in the central bank, deposits in other banks, overnight loans to other banks (known as federal funds in the United States), well-secured call-loans, treasury bills, and other paper of equivalent quality and eligibility to serve as collateral.” (1998, p. 171). 
Por outro lado, a preferência pela liquidez não influi apenas na decisão de escolha de ativos por parte do banco, mas também o montante e o tipo de obrigações que a firma bancária emite para financiar a aquisição de seus ativos. Isso porque para pós-keynesianos a liquidez é definida, com base nos escritos de Minsky $(1975,1982)$, como a capacidade de honrar compromissos contratuais de pagamento em dinheiro. (Ibid, p. 6). Nesse contexto, a liquidez de um ativo não depende apenas da influência do prazo de realização sobre o preço desse ativo - ou seja, do grau de organização dos mercados nos quais esse ativo é transacionado -, mas também do tipo de passivo que foi usado para financiar a sua aquisição. Sendo assim, a liquidez do conjunto de ativos possuídos pelo banco irá depender também da estrutura de passivo da firma bancária. Por exemplo, quanto maior a proporção de depósitos a vista no passivo total do banco, menor será, ceteris paribus, a liquidez da sua carteira de ativos.

Sendo assim, pós-keynesianos defendem a tese de que uma teoria geral da firma bancária deve levar em conta a idéia de que a preferência pela liquidez não afeta apenas a escolha da carteira de ativos do banco, mas também a sua estrutura de passivo, de tal forma que a preferência pela liquidez seria o elemento fundamental para determinar a estratégia dos bancos quanto à composição de seus balanços. Nessa nova teoria da firma bancária a estrutura de passivo dos bancos - e, em particular, o volume de depósitos a vista - deixa de ser uma variável exógena, determinada pelas preferências dos depositantes - tal como ocorre nos modelos da teoria ortodoxa - e torna-se uma variável endógena, determinada pela preferência pela liquidez dos bancos (cf. DE PAULA, 1999, p. 173).

Um aspecto importante que não é tratado pela teoria pós-keynesiana da firma bancária refere-se ao processo de determinação da taxa de juros dos empréstimos e do spread bancário, ou seja, a diferença entre a taxa de juros dos empréstimos e a taxa de juros paga sobre os depósitos a prazo. Uma das poucas referências na literatura pós-keynesiana a respeito do processo de determinação da taxa de juros dos empréstimos é Moore (1988), na qual essa variável aparece determinada com base numa taxa de mark-up constante sobre a taxa de juros básica da economia, ou seja, a taxa de juros sobre as operaçôes de redesconto do banco central. A abordagem de Moore, no entanto, 
é incompatível com a teoria da preferência pela liquidez da firma bancária, pois assume um comportamento excessivamente passivo dos bancos no que se refere à demanda de crédito. Mais precisamente, essa abordagem assume que os bancos simplesmente acomodam toda a demanda de crédito a uma dada taxa de juros, determinada pelo mark-up bancário e pela taxa de juros fixada pelo banco central. Nessa abordagem os bancos não possuem preferência pela liquidez.

A inexistência de qualquer referência ao processo de determinação da taxa de juros dos empréstimos e do spread bancário por parte da teoria pós-keynesiana faz com que a mesma seja uma teoria incompleta a respeito do comportamento dos bancos. Sem uma análise do processo de determinação dessas variáveis não é possível, por exemplo, discutir os efeitos sobre o nível de atividade econômica de um aumento da preferência pela liquidez dos bancos. De fato, o nível de atividade econômica não depende apenas do volume de crédito concedido pelos bancos, mas também dos termos nos quais esse crédito é concedido. Sendo assim, faz-se necessário especificar o processo pelo qual os bancos determinam a taxa de juros dos empréstimos e as possíveis relações dessa variável com a sua estratégia de composição de balanços.

Por outro lado, a teoria pós-keynesiana da firma bancária, devido a sua ênfase na análise das estratégias de composição dos balanços dos bancos, é incapaz de avaliar o impacto sobre o preço e a disponibilidade do crédito bancário de um aumento do grau de concentração do setor bancário. Alguns autores pós-keynesianos como, por exemplo, Dymski (1999) tem ressaltado a importância do processo recente de fusôes e aquisições no setor bancário para a "eficiência social"2 desse setor. Mais precisamente, o aumento do grau de concentração do setor bancário resultante desse processo de fusões e aquisições estaria produzindo uma redução da "eficiência social" dos bancos. Contudo, essas conclusões são baseadas nos modelos convencionais de estrutura de mercado e na literatura empírica de discriminação ban-

2 DYMSKI define "eficiência social" nos seguintes termos: "The social efficiency of the banking system, by extension, measures the extent to which a given organization or set of organizations facilitates the access to capital of borrower groups that have faced historical barriers limiting this access." (1999, p. 7). 
cária e redlining nos mercados urbanos de crédito (Ibid, p. 7), e não na teoria da preferência pela liquidez da firma bancária.

Dado isso, o presente artigo tem como objetivo avançar na elaboração de uma nova teoria pós-keynesiana da firma bancária na qual a composição dos balanços dos bancos seja determinada conjuntamente com a taxa de juros dos empréstimos e o spread bancário. Para tanto será desenvolvido um modelo de firma bancária, tendo como base o capítulo 17 da Teoria Geral de Keynes (1936), no qual os ativos possuídos pelo banco se diferenciam entre si, não só com base na sua taxa explícita de retorno, como também no seu "prêmio de liquidez". Em particular, iremos supor que o "prêmio de liquidez" dos ativos defensivos é uma função da razão entre o montante desses ativos e o volume de depósitos a vista. Dessa forma, o "prêmio de liquidez" desses ativos depende da estrutura de passivo da firma bancária.

No que se refere ao processo de determinação da taxa de juros dos empréstimos, iremos supor, tal como Stiglitz e Weiss (1981), que essa variável é determinada de forma a maximizar o retorno esperado da carteira de empréstimos do banco. A hipótese básica subjacente ao processo de determinação da taxa de juros dos empréstimos é que a proporção esperada de empréstimos pagos é uma função inversa da taxa de juros e do nível percebido de fragilidade financeira. Nesse contexto, a taxa de juros que maximiza o retorno esperado da carteira de empréstimos do banco é independente do volume de crédito bancário, do grau de concentração do setor bancário e da taxa básica de juros.

Iremos supor também que a taxa de juros assim determinada é inferior ao valor de equilíbrio dessa variável, ou seja, ao valor da taxa de juros para o qual haveria igualdade entre demanda e oferta de crédito bancário. Sendo assim, iremos supor a existência de racionamento de crédito. Essa hipótese é de crucial importância para estabelecer o mecanismo pelo qual as variações da taxa de juros básica têm impacto sobre o nível de atividade econômica. No contexto do modelo aqui proposto, um aumento da taxa básica de juros irá induzir os bancos a reduzir a oferta de crédito, aumentando assim o número de projetos de investimento que não conseguem obter financiamento do setor bancário. Trata-se do assim chamado "canal de crédito" da polí- 
tica monetária, enfatizado recentemente pela literatura de inspiração novokeynesiana. ${ }^{3}$

O grau de concentração do setor bancário influencia a estratégia de composição dos balanços dos bancos e o spread bancário por meio da assim chamada "função de retenção de depósitos". O volume de depósitos a vista depende, em parte, da taxa de juros paga pelo banco sobre esses depósitos ${ }^{4}$ e em parte do volume de empréstimos concedido pelo banco. Uma parte dos depósitos criados pelas operações de concessão de crédito por parte do banco não permanecerá no próprio banco, mas será transferido para outros bancos por meio dos cheques emitidos pelos tomadores dos empréstimos.

A extensão na qual cada banco pode esperar reter os depósitos resultantes de suas próprias operações de crédito depende de seu tamanho relativo aos demais bancos (cf. TOBIN, 1998, p. 174). Quanto maior for o tamanho do banco relativamente aos demais bancos, maior será a proporção dos depósitos criados pelas suas operações de crédito que ele será capaz de reter. Sendo assim, o grau de concentração bancária determina, em conjunto com a taxa de juros paga sobre os depósitos a vista e o volume de empréstimos concedido pelo banco, o volume total de depósitos a vista.

Sendo assim, a teoria geral da firma bancária aqui proposta combina a teoria pós-keynesiana da preferência pela liquidez dos bancos com o modelo de racionamento de crédito de Stiglitz e Weiss com alguns elementos da teoria da firma bancária de James Tobin. O resultado dessa combinação é um modelo geral de comportamento dos bancos no qual a estratégia de composição dos balanços é determinada conjuntamente com a taxa de juros dos empréstimos e o spread bancário. As principais conclusões sobre o comportamento dos bancos obtidas a partir desse modelo são as seguintes:

3 Alguns exemplos dessa literatura são GERTLER (1988), BERNANKE \& BLINDER (1988), BERNANKE (1993), BERNANKE \& GERTLER (1995), CECCHETI (1995), WALSH (2001, cap. 7), STIGLITZ \& GREENWALD (2003).

4 A taxa de juros sobre os depósitos a vista não é necessariamente uma taxa explícita de juros, mas pode ser entendida, tal como sugerido por KLEIN (1971), como um retorno implícito para os depositantes na forma de acesso preferencial a linhas de crédito, isenção total ou parcial de taxas ou tarifas de manutenção das contas de depósito a vista etc. (cf. KLEIN, 1971, p. 215). 
1. O spread bancário é uma função crescente do grau de concentração existente no setor bancário e decrescente da taxa básica de juros, ou seja, os bancos irão aumentar o spread como resposta a um aumento do grau de concentração na "indústria bancária" e irão reduzir o spread como resposta a um aumento da taxa básica de juros.

2. Um aumento da taxa básica de juros não afeta a taxa de juros cobrada pelos bancos sobre os seus empréstimos, mas reduz o volume ofertado de crédito.

3. Variações do grau de concentração do setor bancário têm efeito ambíguo sobre o volume ofertado de crédito por parte dos bancos.

Dado isso, o presente artigo está estruturado em quatro seções, incluindo a introdução. A seção a seguir apresenta a estrutura básica do modelo geral de firma bancária. A seção 2 está dedicada a resolução do modelo apresentado na segunda seção. A última seção resume as conclusões obtidas ao longo do artigo.

\section{A ESTRUTURA BÁSICA DO MODELO GERAL DE FIRMA BANCÁRIA}

Consideremos uma firma bancária que possui em seu balanço duas classes de ativos e duas classes de passivos. No lado do ativo, o banco mantém uma classe de ativos com alta rentabilidade e baixa liquidez, a qual denominaremos de empréstimos (L), e outra classe de ativos com baixa rentabilidade e alta liquidez, a qual denominaremos de ativos defensivos. Uma parte desses ativos é constituída pelas reservas compulsórias exigidas pelo banco central, as quais são uma proporção $\tau$ do volume de depósitos a vista (D) mantidos no banco em consideração. A diferença entre o montante de ativos defensivos e as reservas compulsórias se constitui na posição defensiva líquida (R) do banco (cf. TOBIN, 1998, p. 175), cuja função é evitar os custos (explícitos ou implícitos) associados a uma redução não antecipada dos depósitos a vista. Dado isso, o volume de ativos (A) possuído pelo banco pode ser expresso por: 


$$
A=\tau D+R+L
$$

No lado do passivo, o banco obtém recursos de duas fontes: depósitos a vista e capital próprio (W). Sendo F o volume de recursos obtidos pelo banco, temos então que:

$$
F=D+W
$$

A condição de consistência do balanço do banco exige que $A=F$, portanto:

$$
W=R+L-(1-\tau) D
$$

\subsection{Composição da Carteira de Ativos}

\subsubsection{Empréstimos}

Seja $E_{1}$ a taxa esperada de retorno da carteira de empréstimos do banco. A taxa esperada de retorno é determinada com base na seguinte expressão:

$$
E_{l}=\gamma r_{l}
$$

Onde: $\gamma$ é a proporção esperada dos empréstimos pagos, $r_{l}$ é a taxa de juros dos empréstimos.

Tal como Stiglitz e Weiss (1981), supõe-se que a proporção esperada de empréstimos pagos é uma função decrescente da taxa de juros dos empréstimos. Isto porque, devido aos problemas de seleção adversa e risco moral gerados pela assimetria de informação entre tomadores e emprestadores -, um aumento da taxa de juros irá (i) reduzir a qualidade média dos tomadores de crédito e (ii) reduzir a qualidade média (ou seja, aumentar o risco) dos projetos de investimento. Esses efeitos deverão, portanto, aumentar a proporção de tomadores inadimplentes na carteira total de empréstimos do banco. 
A proporção esperada dos empréstimos pagos irá depender também do nível de fragilidade financeira dos tomadores, tal como é percebido pelo banco. Se definirmos o nível percebido de fragilidade financeira, tal como Dreizzen (1985), como a razão entre o fluxo de encargos financeiros da firma (juros e amortizações sobre o principal) e o fluxo de fundos autogerados pela mesma (lucros), podemos expressar a fragilidade financeira $(f)$ percebida pela seguinte equação :

$$
f=\frac{a+r_{l}}{r_{k}} \alpha_{k} \quad ; \alpha_{k}=\frac{L}{K}
$$

Onde: $a$ é o coeficiente de amortização do principal, $\mathrm{r}_{\mathrm{k}}$ é a taxa de retorno sobre o capital das empresas não-financeiras, $\alpha_{\mathrm{k}}$ é o grau de endividamento das empresas não-financeiras.

Dado isso, podemos expressar a proporção esperada dos empréstimos pagos pela seguinte equação:

$$
\gamma=\gamma\left(f, r_{l}\right) \quad ; \quad \frac{\partial \gamma}{\partial f}<0 \quad ; \quad \frac{\partial \gamma}{\partial r_{l}}<0
$$

Tendo em vista o tratamento matemático do modelo, iremos supor que a função $\gamma($.$) é linear do seguinte tipo :$

$$
\gamma=\gamma_{0}-\gamma_{1} r_{l}-\gamma_{s} f \quad ; \quad \gamma_{0}>0, \gamma_{1}>0, \gamma_{2}>0
$$

Substituindo (5) em (7) e a resultante em (4), obtemos:

$$
E_{l}=\left(\gamma_{0}-\gamma_{2} a r_{k}^{-1}\right) r_{l}-\left(\gamma_{1}+\gamma_{2} \alpha_{k} r_{k}^{-1}\right) r_{l}^{2}
$$

Observa-se na equação (8) que a taxa esperada de retorno dos empréstimos é uma função não-linear da taxa de juros dos empréstimos. Em particular, pode-se verificar facilmente que a relação entre $E_{l}$ e $r_{l}$ é tal qual aquela apresentada pela Figura 1, o que implica dizer que existe um determinado nível da taxa de juros que maximiza o retorno esperado da carteira de empréstimos do banco. 
FIGURA 1

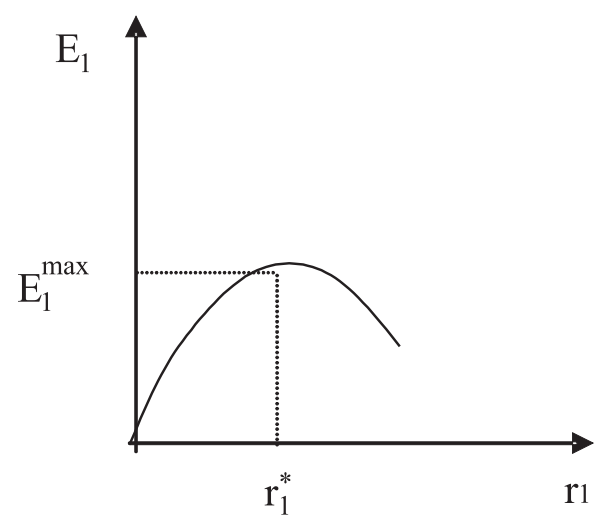

Para calcular o valor da taxa de juros que maximiza o retorno esperado da carteira de empréstimos do banco basta diferenciar (8) com respeito a $r_{l} \mathrm{e}$ igualar a expressão resultante a zero. Temos, então, que:

$$
r_{l}^{*}=\frac{1}{2}\left\{\frac{\gamma_{0}-\gamma_{2} a r_{k}^{-1}}{\gamma_{1}+\gamma_{2} \alpha_{k} r_{k}^{-1}}\right\}
$$

Seja $L$ o volume de empréstimos concedido pelo banco. Os modelos tradicionais de firma bancária supóem que o banco se defronta com uma curva de demanda de empréstimos negativamente inclinada no plano $<\mathrm{r}_{1}, \mathrm{~L}>$ e que o problema do banco é escolher um ponto sobre essa curva. Nesse contexto, a firma bancária não pode escolher $\mathrm{r}_{1} \mathrm{e} \mathrm{L}$ de forma independente entre si: a escolha de um determinado valor da taxa de juros implica, dada a curva de demanda de empréstimos, um certo montante demandado de crédito. Se os bancos ofertarem todo o crédito que é demandado pelos tomadores, seguese que o volume de empréstimos será determinado a partir do momento em que os mesmos definirem o valor da taxa de juros dos empréstimos.

Essa não será, contudo, a abordagem adotada no presente modelo. Iremos supor que os bancos racionam crédito, ou seja, concedem um volume de crédito menor do que o demandado pelas firmas à taxa de juros fixada pelos primeiros. Uma condição necessária e suficiente para o racionamento de crédito é que o nível da taxa de juros que maximiza o retorno esperado da 
carteira de empréstimos do banco seja menor do que o nível da taxa de juros para o qual haveria igualdade entre demanda e oferta de empréstimos.

Nesse contexto, o banco pode escolher $r_{l} e L$ de forma independente. Em outras palavras, a escolha a respeito do valor a ser fixado da taxa de juros não impõe nenhuma restrição ao montante de crédito que pode ser concedido pelo banco. A única função da curva de demanda dos empréstimos no modelo em consideração é determinar - dados os valores de $r_{l} e L$ fixados pelo banco - o montante do racionamento de crédito.

\subsubsection{Ativos Defensivos}

Os ativos defensivos possuídos pelo banco são constituídos pelas reservas requeridas (compulsórias) pelo banco central e pela posição defensiva líquida. Tais ativos englobam não apenas as reservas em papel-moeda, como também depósitos em outros bancos, empréstimos no mercado interbancário e obrigações do Tesouro.

Se a posição defensiva líquida do banco for negativa, isso significa que o volume de ativos defensivos possuídos pelo banco é inferior a reservas requeridas pelo banco central. Nesse caso, o banco será obrigado a tomar empréstimos no mercado interbancário ou a recorrer ao redesconto do banco central.

Por simplicidade iremos supor que as reservas em papel-moeda, os depósitos em outros bancos, os empréstimos no mercado interbancário e as obrigações do Tesouro são substitutos perfeitos, de tal forma que a taxa de retorno é igual para todos esses ativos. Seja $r$ a taxa de juros das obrigações do Tesouro. Daqui se segue que se o banco estiver mantendo uma posição defensiva líquida positiva, então ele receberá uma remuneração igual a $r$ sobre o valor de sua posição líquida. Por outro lado, se o banco estiver mantendo uma posição defensiva líquida negativa, então ele pagará uma taxa igual a $r$ sobre o valor de sua posição negativa.

Seja $R_{R}$ a taxa própria de juros da posição defensiva líquida do banco. $O$ conceito de taxa própria de juros é uma medida do rendimento total de um 
ativo, incluindo não apenas o rendimento monetário explícito devido a sua posse ou uso produtivo do mesmo, mas também o rendimento implícito na forma de conveniência, segurança e flexibilidade (cf. CARVALHO, 1992, p. 81). O rendimento implícito nada mais é do que o prêmio de liquidez do ativo, ou seja, o rendimento que o agente estaria disposto a sacrificar em troca da posse de ativos líquidos.

Isso posto, seja $l_{R}$ o prêmio de liquidez da posição defensiva líquida do banco. Temos que:

$$
R_{R}=r+l_{R}
$$

O prêmio de liquidez da posição defensiva líquida não é constante, mas depende da relação entre o valor da posição líquida e o volume de depósitos a vista. Quanto maior o volume de depósitos a vista relativamente ao valor da posição líquida do banco, menor será a margem de segurança do banco no caso de uma redução inesperada dos depósitos a vista. Em outras palavras, quanto menor for a relação (R/D), menor será a redução dos depósitos que o banco pode enfrentar sem ter que recorrer ao redesconto do banco central ou a empréstimos no mercado interbancário. Quanto menor a margem de segurança, maior será o valor da liquidez para o banco, ou seja, maior será o rendimento que o mesmo estará disposto a sacrificar em troca da posse de ativos líquidos. Sendo assim, o prêmio de liquidez da posição defensiva líquida do banco pode ser expresso por:

$$
\begin{array}{ll}
l_{R}=l\left(\frac{R}{D}\right) & ; \quad \frac{\partial l_{R}}{\partial(R / D)}<0 \\
\text { ou }: & \text {; } l_{0}>0, l_{1}>0, l_{2}>0
\end{array}
$$

Substituindo (11b) em (10), temos que:

$$
R_{R}=r+l_{0}-l_{1} R+l_{2} D
$$




\subsection{Estrutura de Passivo do Banco}

\subsubsection{Depósitos a Vista}

A maior parte dos modelos convencionais de firma bancária toma o volume de depósitos como uma variável exógena que não está sob o controle do banco. Para pós-keynesianos, contudo, o volume de depósitos é uma variável endógena determinada pelo volume de empréstimos concedido pelo banco. Isso porque a criação de depósitos se dá por intermédio da realização de empréstimos: no momento em que o banco concede um empréstimo, ele credita um depósito de igual valor na conta do tomador desse empréstimo.

Contudo, à medida que o tomador utiliza os recursos emprestados para financiar o seu projeto de investimento, uma parte do depósito original é transferida para outros bancos por meio de cheques e ordens de pagamento ou para o setor não-bancário por intermédio de saques em papel-moeda. Isto significa que após um certo intervalo de tempo o banco irá reter apenas uma fração dos depósitos originalmente criados pelas suas operações de crédito.

A proporção dos depósitos gerados pelas operações de crédito que o banco consegue reter em seu balanço será uma função crescente do tamanho do banco em consideração relativamente aos demais bancos. Quanto a esse efeito, Tobin afirma que:

"The degree to which a bank can expect to retain deposits resulting from its own loans depends on its size relative to other banks. If a bank is the only one in the community, it will retain more than if the local payees of the borrower's chechs are scattered among several banks. But even a monopoly bank will lose deposits as transactions spread to other areas of the economy. And a national monopoly bank, if one existed, would still face leakages to currency bolding, foreign balances, and other assets (...). “(1998, p. 174). 
Dessa afirmação podemos inferir que a proporção esperada de depósitos retidos é uma função do grau de concentração do setor bancário: quanto maior o grau de concentração, menor será o "vazamento" dos depósitos criados pelo banco por suas operaçóes de crédito para outros bancos ou para o setor não-bancário da economia.

Uma terceira variável que influencia o volume de depósitos a vista que o banco consegue captar é a taxa de juros paga pelo mesmo sobre esses depósitos. A taxa de juros sobre os depósitos a vista influencia o volume de depósitos porque influencia a decisão do público a respeito da proporção de saldos transacionais mantidos na forma de papel-moeda e na forma de depósitos a vista. Quanto maior a taxa de juros dos depósitos, menor será a proporção dos saldos transacionais que o público desejará manter na forma de papel-moeda e, portanto, menor será o "vazamento" dos depósitos criados pelas operações de crédito do banco para o setor não-bancário da economia.

Deve-se observar que a taxa de juros dos depósitos a vista não é necessariamente uma taxa explícita de juros. De acordo com Klein (1971), ela pode ser entendida como uma remuneração implícita ao depositante na forma de acesso preferencial a linhas de crédito, isenção total ou parcial de tarifas de manutenção de conta etc. Esses serviços são uma remuneração implícita para o depositante, mas representam um custo econômico para o banco, de tal forma que deve ser levado em conta pelo banco na sua tomada de decisão.

Com base nessas considerações, a função de depósitos a vista pode ser apresentada por intermédio da seguinte equação:

$$
D=D\left(r_{d}\right)+\phi\left(L, \frac{A_{i}}{A}\right) \quad ; \frac{\partial \phi}{\partial L}>0 ; \quad \frac{\partial \phi}{\partial\left(A_{i} / A\right)}>0
$$

Onde: $r_{d}$ é a taxa de juros dos depósitos a vista, $A_{i}$ é o ativo total do i-ésimo banco, $A$ é o ativo total do sistema bancário, $\phi$ é a função de retenção de depósitos, ou seja, a função que relaciona o volume de depósitos a vista com o montante de empréstimos concedido pela firma bancária. 
A versão linear de (13) é dada pela seguinte expressão:

$$
D=\phi_{0}+\phi_{1} r_{d}+\phi_{2} L+\phi_{3} s_{i} \quad 1 \quad ; \phi_{0}>0, \phi_{1}>0, \phi_{2}>0, \phi_{3}>0
$$

Onde: $s_{i}$ é a fração dos ativos totais do sistema bancário de propriedade do i-ésimo banco.

\subsubsection{Capital Próprio}

Iremos supor que o banco possui um montante de capital próprio igual a W, determinado residualmente pela equação (3). Por simplicidade, não estamos considerando a existência de nenhum requisito mínimo de capital próprio por parte do banco central, de tal forma que $\mathrm{W}$ se ajusta passivamente aos valores de R, D e L decididos pelo banco. Contudo, iremos supor que os investidores exigem uma remuneração mínima $r_{w}$ sobre o capital aplicado no banco. Daqui se segue que o custo do capital próprio para o banco é dado pela seguinte expressão:

$$
C_{w}=r_{w}(R+L-(1-\tau) D)
$$

\subsection{A Função Custo do Banco}

A firma bancária não é apenas uma coleção de ativos e passivos, mas uma empresa que produz serviços para os agentes econômicos, quais sejam: a administração dos mecanismos de pagamento da economia e o monitoramento do comportamento dos tomadores de empréstimo (cf. FREIXAS \& ROCHET, 1997, cap. 3; KLEIN, 1971, p. 206; SANTOMERO, 1984, p. 577-78). Toda a produção de bens e serviços envolve custos econômicos (implícitos ou explícitos) que podem ser expressos por intermédio da função custo, ou seja, da função que relaciona a quantidade produzida com o custo mínimo de produção dessa quantidade.

No caso da firma bancária existe uma certa dificuldade em medir com precisão a quantidade de serviços que está sendo oferecida pelo banco (cf. KLEIN, 1971, p. 205). Dessa forma, a melhor maneira de apresentar a fun- 
ção custo do banco é relacionar o custo de produção dos serviços bancários com o volume de depósitos a vista e com o montante de empréstimos concedidos pelo banco. Essas variáveis servem como uma proxy para a quantidade de serviços produzidos pelo banco.

Isso posto, a função custo da firma bancária pode ser expressa por:

$$
\begin{aligned}
& C=C(D, L) ; \frac{\partial C}{\partial D}=c_{1} D ; \frac{\partial C}{\partial L}=c_{2} L \\
& \text { cl }>0, \mathrm{c} 2>0
\end{aligned}
$$

Observamos na equação (16) que o custo marginal dos depósitos bancários é crescente no volume de depósitos. De forma análoga, o custo marginal dos empréstimos é crescente no volume de empréstimos.

\section{O PROBLEMA DE MAXIMIZAÇAOO DO BANCO: A ESCOLHA DA COMPOSIÇÃO ÓTIMA DE BALANÇO E DO SPREAD ÓTIMO}

Com base na discussão feita na seção anterior, podemos apresentar a função lucro do banco com base na seguinte expressão:

$$
\pi=E_{l} L+R_{R} R-D r_{d}-r_{w}[R+L-(1-\tau) D]-C(D, L)
$$

onde: $\pi$ é o lucro econômico do banco.

O banco possui 4 variáveis de controle, a saber: o volume de empréstimos (L), o valor da posição defensiva líquida $(\mathrm{R})$, a taxa de juros dos empréstimos $\left(r_{1}\right)$ e a taxa de juros dos depósitos a vista $\left(r_{d}\right)$. O volume de depósitos a vista não é uma variável de controle porque o mesmo é determinado por $\mathrm{L}$ e $r_{d}$ por intermédio da equação (14).

As variáveis de estado são a participação do banco no total de ativos do setor bancário $\left(s_{i}\right)$, a proporção de reservas requeridas pelo banco central $(\tau)$, a taxa de retorno das obrigaçốes do Tesouro $(r)$, o grau de endividamento das empresas $\left(\alpha_{k}\right)$, a taxa de retorno sobre o capital das empresas não-finan- 
ceiras $\left(\mathrm{r}_{\mathrm{k}}\right)$, e a taxa mínima de retorno exigida pelos investidores sobre o capital aplicado no banco $\left(\mathrm{r}_{\mathrm{w}}\right)$.

Iremos supor que o banco escolhe os valores de $\mathrm{L}, \mathrm{R}, \mathrm{r}_{1}$ e $\mathrm{r}_{\mathrm{d}}$ de forma a obter o maior lucro possível. Assim sendo, o problema do banco é:

$$
\begin{aligned}
& \operatorname{Max} \pi=\left\{\left[\gamma_{0}-\gamma_{2} a r_{k}^{-1}\right] r_{l}-\left[\gamma_{1}+\gamma_{2} \alpha_{k} r_{k}^{-1}\right] r_{l}^{2}\right\} L+\left\{r+l_{0}-l_{1} R+l_{2}\left(\phi_{0}+\phi_{1} r_{d}+\phi_{2} L+\phi_{3} s_{i}\right)\right\} \\
& R-\left[\phi_{0}+\phi_{1} r_{d}+\phi_{2} L+\phi_{3} s_{i}\right] r_{d}-r_{w}\left\{R+L-(1-\tau)\left[\phi_{0}+\phi_{1} r_{d}+\phi_{2} L+\phi_{3} s_{i}\right]\right\}- \\
& C\left(L,\left[\phi_{0}+\phi_{1} r_{d}+\phi_{2} L+\phi_{3} s_{i}\right]\right.
\end{aligned}
$$

As condições de primeira ordem para maximização de lucro da firma bancária são dadas pelas seguintes expressões:

$$
\begin{aligned}
& \frac{\partial \pi}{\partial L}= E_{L}^{*}-\left[\phi_{2}+c_{1} \phi_{1}\right] r_{D}-\left[c_{2}+\phi_{2}^{2} c_{1}\right] L-c_{1} \phi_{0} \phi_{2}-c_{1} \phi_{2} \phi_{3} s_{i}-r_{w}\left[1-(1-\tau) \phi_{2}\right]=0 \\
& \frac{\partial \pi}{\partial r_{l}}=\left\{\gamma_{0}-\gamma_{2} a r_{k}^{-1}\right\}-2\left\{\gamma_{1}+\gamma_{2} \alpha_{k} r_{k}^{-1}\right\} r_{l}=0 \\
& \frac{\partial \pi}{\partial R}=\left\{r+l_{0}-l_{1} R+l_{2}\left[\phi_{0}+\phi_{1} r_{D}+\phi_{2} L+\phi_{3} s_{i}\right]-l_{1} R\right\}=0 \\
& \frac{\partial \pi}{\partial r_{D}}= l_{2} R \phi_{1}-\left[\phi_{0}+\phi_{1} r_{D}+\phi_{2} L+\phi_{3} s_{i}\right]-(1-\tau) \phi_{1}+r_{w}(1-\tau) \phi_{1} \\
&-\phi_{1} c_{1}\left[\phi_{0}+\phi_{1} r_{D}+\phi_{2} L+\phi_{3} s_{i}\right]=0
\end{aligned}
$$

Colocando L em evidência na equação (19a), temos, após os algebrismos necessários, que: ${ }^{5}$

$$
L=\frac{1}{\left(c_{2}+\phi_{2}^{2} c_{1}\right)} E_{L}^{*}-\left\{\left[\begin{array}{c}
{\left[\phi_{2}+c_{1} \phi_{1}\right]} \\
{\left[c_{2}+\phi_{2}^{2} c_{1}\right]}
\end{array}\right\} r_{D}-\left\{\begin{array}{c}
c_{1} \phi_{2} \phi_{3} \\
{\left[c_{2}+\phi_{2}^{2} c_{1}\right]}
\end{array}\right\} s_{i}-\left\{\frac{\left[1-(1-\tau) \phi_{2}\right]}{\left[c_{2}+\phi_{2}^{2} c_{1}\right]}\right\} r_{w}\right.
$$

A equação (20) apresenta o volume de empréstimos concedido pelo banco como uma função do retorno esperado da carteira de empréstimos, da taxa de

5 Para simplificar o tratamento matemático do modelo estamos supondo que : $\phi_{0}=0$. 
juros dos depósitos a vista, da participação do banco no volume total de ativos do sistema bancário e da taxa mínima de retorno sobre o capital próprio.

Para calcular o impacto sobre o volume de crédito bancário de uma variação em cada uma dessas variáveis basta calcular as derivadas parciais de $\mathrm{L}$ com respeito a $\mathrm{E}_{\mathrm{l}}, \mathrm{r}_{\mathrm{d}}$, $\mathrm{s}_{\mathrm{i}}$ e $\mathrm{r}_{\mathrm{w}}$. Temos que:

$$
\begin{gathered}
\frac{\partial L}{\partial E_{L}^{*}}=\frac{1}{\left(c_{2}+\phi_{2}^{2} c_{1}\right)}>0 \\
\frac{\partial L}{\partial r_{D}}=-\frac{\left[\phi_{2}+c_{1} \phi_{1}\right]}{c_{2}+\phi_{2}^{2} c_{1}}<0 \\
\frac{\partial L}{\partial s_{i}}=-\frac{c_{1} \phi_{2} \phi_{3}}{\left[c_{2}+\phi_{2}^{2} c_{1}\right]}<0 \\
\frac{\partial L}{\partial r_{w}}=-\frac{\left[1-(1-\tau) \phi_{2}\right]}{\left[c_{2}+\phi_{2} c_{1}\right]}<>0
\end{gathered}
$$

Resolvendo (19b) para $r_{l}$, obtemos a seguinte expressão:

$$
r_{L}^{*}=\frac{1}{2}\left\{\frac{\gamma_{0}-\gamma_{1} a r_{k}^{-1}}{\gamma_{1}+\gamma_{2} \alpha_{k} r_{k}^{-1}}\right\}
$$

A equação (22) apresenta a taxa de juros dos empréstimos que maximiza o lucro do banco. Podemos observar que a taxa de juros que maximiza o lucro do banco é igual ao valor da taxa de juros que maximiza o retorno esperado da carteira de empréstimos da firma bancária. Isso significa dizer que as decisões do banco quanto à composição de seus ativos e passivos não têm nenhuma influência na sua decisão sobre o valor da taxa de juros dos empréstimos.

Dessa forma, a taxa de juros dos empréstimos é independente de variações no grau de concentração do setor bancário, do coeficiente de reservas reque- 
ridas pelo banco central, da taxa de retorno das obrigaçóes do governo e da taxa mínima de retorno sobre o capital próprio do banco. As únicas variáveis exógenas que afetam a taxa de juros dos empréstimos são o grau de endividamento das empresas, o coeficiente de amortização das dívidas e a taxa de retorno sobre o capital das empresas não-financeiras.

Substituindo (20) em (19c), temos que :

$$
\begin{aligned}
R= & \frac{1}{2}\left[\frac{l_{2} \phi_{2}}{l_{1}\left(c_{2}+\phi_{2}^{2} c_{1}\right)}\right] E_{L}^{*}-\frac{1}{2}\left\{\frac{l_{2} \phi_{2}^{2}(1-\tau)-l_{2} \phi_{1} c_{2}}{l_{1}\left(c_{2}+\phi_{2}^{2} c_{1}\right)}\right\} r_{D}+\frac{1}{2}\left\{\frac{l_{2} c_{2} \phi_{3}\left(\phi_{2}^{2}-1\right)-l_{2} \phi_{3} \phi_{2}^{2} c_{1}}{l_{1}\left(c_{2}+\phi_{2}^{2} c_{1}\right)}\right\} s_{i} \\
& +\frac{1}{2}\left\{\frac{r+l_{0}}{l_{1}}\right\}
\end{aligned}
$$

A equação (23) apresenta a posição defensiva líquida do banco como uma função da taxa esperada de retorno da carteira de empréstimos, da taxa de juros sobre os depósitos a vista, da participação do banco no ativo total do sistema bancário e da taxa de juros das obrigações do Tesouro.

De (23) temos que:

$$
\frac{\partial R}{\partial E_{L}^{*}}=\frac{1}{2}\left[\frac{l_{2} \phi_{2}}{l_{1}\left(c_{2}+\phi_{2}^{2} c_{1}\right)}\right]>0
$$

Ou seja, um aumento da taxa esperada de retorno dos empréstimos irá produzir um aumento da posição defensiva líquida dos bancos. Esse resultado está diretamente relacionado com a "função de retenção de depósitos" e com o "prêmio de liquidez" dos ativos defensivos. Com efeito, sabemos por (21a) que um aumento da taxa esperada de retorno dos empréstimos irá induzir os bancos a aumentar a oferta de crédito. Se o banco aumentar o volume de empréstimos, então, pela função de retenção de depósitos”, haverá um aumento do volume de depósitos a vista, dados $r_{d}$ e $s_{i}$. Mas um aumento do volume de depósitos relativamente ao valor da posição líquida do banco irá aumentar o "prêmio de liquidez" dos ativos defensivos, induzindo os bancos a aumentar a sua posição defensiva líquida. Daqui se segue que empréstimos e ativos defensivos não são ativos substitutos, mas sim complementares. 
Diferenciando (23) com respeito a $r_{D}$ temos:

$$
\frac{\partial R}{\partial r_{D}}=-\frac{1}{2} \frac{l_{2}}{l_{1}}\left\{\frac{\phi_{2}^{2}(1-\tau)-\phi_{1} c_{2}}{c_{2}+\phi_{2}^{2} c_{1}}\right\}
$$

O sinal de (24b) é ambíguo porque o numerador pode ser positivo ou negativo dependendo da sensibilidade dos depósitos a vista a variaçóes da taxa de juros, ou seja, dependendo do valor de $\phi_{1}$. Com efeito, pode-se provar que:

$$
\frac{\partial R}{\partial r_{d}}>0 \Leftrightarrow \phi_{1}>\frac{\phi_{2}(1-\tau)}{c_{2}}
$$

$\mathrm{Na}$ expressão (25) observa-se que se os depósitos a vista forem muito sensíveis às variações da taxa de juros, então a posição defensiva líquida do banco será uma função crescente de $r_{d}$. Contudo, se essa sensibilidade for inferior a um certo valor crítico, dado pelo lado direito da segunda desigualdade em (25), então a posição defensiva líquida será uma função decrescente da taxa de juros sobre os depósitos a vista.

Diferenciando (23) com respeito a $s_{i}$ temos: $^{6}$

$$
\frac{\partial R}{\partial s_{i}}=-\frac{1}{2}\left(\frac{l_{2} \phi_{3}}{l_{1}}\right) \frac{c_{2}}{c_{2}+\phi_{2}{ }^{2} c_{1}}<0
$$

Na equação (24c) observamos que um aumento da participação do banco no ativo total do sistema bancário irá produzir uma redução da posição defensiva líquida do banco. Isso ocorre porque, com base na equação (2lc), um aumento de $s_{i}$ leva o banco a reduzir o volume de crédito, o que, por sua vez, reduz a criação de depósitos por intermédio da equação (14). Dado R, uma redução de $\mathrm{D}$ faz com que o prêmio de liquidez dos ativos defensivos diminua, levando o banco a reduzir a sua posição defensiva líquida.

6 Para obter esse resultado estamos supondo que $c_{1}=c_{2}$. 
Finalmente, diferenciando (23) com respeito a $r$, obtemos a seguinte expressão:

$$
\frac{\partial R}{\partial r}=\frac{1}{2} \frac{1}{l_{1}}>0
$$

Ou seja, um aumento da taxa de retorno das obrigações do Tesouro irá levar o banco a aumentar a sua posição defensiva líquida. A intuição desse resultado é bastante simples: um aumento da taxa básica de juros irá aumentar a taxa total de retorno dos ativos defensivos - a "taxa própria de juros" - induzindo o banco a aumentar a sua posição defensiva líquida.

Substituindo (20) e (23) em (19d), pode-se chegar à seguinte expressão:

$$
r_{d}=\frac{A_{1}}{A_{0}} E_{L}^{*}+\frac{A_{2}}{A_{0}} r_{w}-\frac{A_{3}}{A_{0}} s_{i}+\frac{A_{4}}{A_{0}}\left(r+l_{0}\right)-\frac{(1-\tau) \phi_{1}}{A_{0}}
$$

onde:

$$
\begin{aligned}
& A_{0}=\left\{\frac{(1-\tau)\left[\phi_{1}\left(l_{2}^{2} \phi_{2}^{2}+2 l_{1} c_{2}\right)+2 l_{1} c_{1} \phi_{1}^{3}\right]+2 l_{1} \phi_{1}^{2}\left[c_{1} c_{2}+\phi_{2}^{2} c_{1}^{2}\right]}{2 l_{1}\left(c_{2}+\phi_{2}^{2} c_{1}\right)}\right\} \\
& -\left\{\frac{(1-\tau)\left[(1-\tau) \phi_{2}^{2}\left(1-c_{1} \phi_{1}\right)-c_{1} \phi_{1} \phi_{2}\right]}{2 l_{1}\left(c_{2}+\phi_{2}^{2} c_{1}\right)}\right\}-\left\{\frac{\phi_{1}^{2}\left[l_{2} c_{2}+c_{1}^{2} \phi_{2}\right]}{2 l_{1}\left(c_{2}+c_{1} \phi_{2}^{2}\right)}\right\} \\
& A_{1}=\left\{\frac{\phi_{1} \phi_{2}\left[l_{2}^{2}-2 l_{1} c_{1}\right]-(1-\tau) \phi_{2} 2 l_{1}}{2 l_{1}\left(c_{2}+\phi_{2}^{2} c_{1}\right)}\right\} \\
& A_{2}=\left\{\frac{(1-\tau) \phi_{1}\left[c_{2}+c_{1} \phi_{2}^{2}\right]}{c_{2}+\phi_{2}^{2} c_{1}}\right\} \\
& A_{3}=\left\{\frac{(1-\tau) \phi_{3} 2 l_{1}\left[c_{2}+c_{1} \phi_{2}^{2}\right]+\phi_{1} \phi_{3} c_{2}\left[l_{2}^{2}+2 l_{1} c_{1}\right]+2 l_{1} \phi_{2}^{2} c_{1}^{2} \phi_{1} \phi_{3}}{2 l_{1}\left(c_{2}+\phi_{2}^{2} c_{1}\right)}\right\}
\end{aligned}
$$




$$
A_{4}=\left\{\frac{l_{2} \phi_{1}}{2 l_{1}}\right\}
$$

Primeiramente, temos que determinar os sinais das expressões (27a)-(27d), pois, do contrário, não seremos capazes de analisar o impacto sobre a taxa de juros dos depósitos a vista de variações da taxa esperada de retorno dos empréstimos, da taxa mínima de retorno sobre o capital próprio, da participação do banco no ativo total do sistema bancário e da taxa de juros das obrigações do Tesouro.

Comecemos inicialmente com as expressões (27e), (27d) e (27c), uma vez que não há nenhuma ambigüidade quanto ao sinal das mesmas: nos três casos os coeficientes são positivos.

O sinal da expressão (27a) é o mais difícil de ser analisado devido à complexidade da mesma. Contudo, podemos obter uma intuição sobre o sinal desse coeficiente fazendo o seguinte raciocínio. Se $\phi_{1}$ for igual a zero, então a expressão do coeficiente $\mathrm{A}_{0}$ se reduz para:

$$
A_{0}=-\frac{(1-\tau)^{2} \phi_{2}^{2}}{2 l_{1}\left(c_{2}+\phi_{2}^{2} c_{1}\right)}<0
$$

Por outro lado, diferenciando $(27 \mathrm{a})$ com respeito à $\phi_{1}$ obtém-se a seguinte expressão:

$$
\begin{aligned}
\frac{\partial A_{0}}{\partial \phi_{1}} & =\left\{\frac{(1-\tau)\left[l_{2}^{2} \phi_{2}^{2}+2 l_{1} c_{2}+6 l_{1} c_{1} \phi_{1}^{2}\right]+4 l_{1} c_{1} \phi_{1}\left[c_{2}+c_{1} \phi_{2}^{2}\right]}{2 l_{1}\left[c_{2}+\phi_{2}^{2} c_{1}\right]}\right\} \\
& +\left\{\frac{c_{1} \phi_{2}\left[(1-\tau)+\phi_{2}\right]}{2 l_{1}\left(c_{2}+\phi_{2}^{2} c_{1}\right)}\right\}-\left\{\frac{2 \phi_{1}\left[l_{2} c_{2}+c_{1}^{2} \phi_{2}^{2}\right]}{2 l_{1}\left(c_{2}+\phi_{2}^{2} c_{1}\right)}\right\}
\end{aligned}
$$


Uma condição suficiente para que a expressão (28) tenha sinal positivo é que:

$$
c_{1} \phi_{2}\left[(1-\tau)+\phi_{2}\right]>2 \phi_{1}\left[l_{2} c_{2}+c_{1}^{2} \phi_{2}^{2}\right\rfloor
$$

A condição (29a) será atendida se $\phi_{1}$ estiver abaixo de um certo valor crítico dado por:

$$
\phi_{1}<\frac{1}{2}\left\{\frac{c_{1} \phi_{2}\left[(1-\tau)+\phi_{2}\right]}{l_{2} c_{2}+c_{1}^{2} \phi_{2}^{2}}\right\}
$$

Em palavras: o coeficiente $A_{0}$ será com certeza uma função crescente em $\phi_{1}$ se o valor deste parâmetro estiver abaixo de um certo valor crítico definido pela expressão (29b). Nesse contexto, é possível que $\mathrm{A}_{0}$ seja positivo para um valor de $\phi_{1}$ abaixo desse valor crítico. Essa possibilidade é ilustrada pela Figura 2.

FIGURA 2

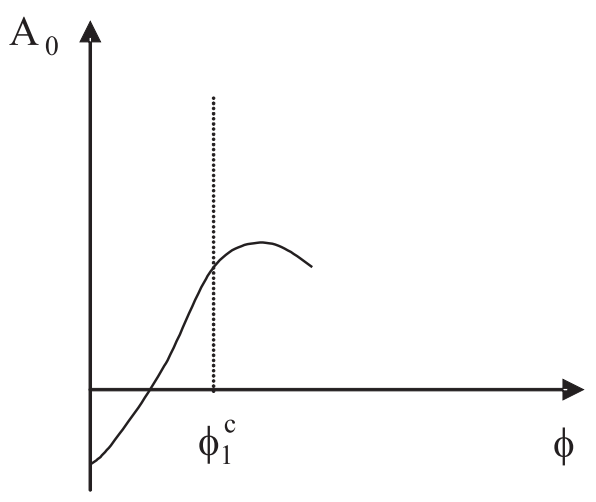

Com base nesse raciocínio iremos supor que a sensibilidade dos depósitos a vista com respeito às variações da taxa de juros é tal que $\mathrm{A}_{0}$ é positivo.

Resta analisar o sinal da expressão (27b). Tal como ocorre na expressão (27a), o sinal de (27b) é ambíguo, podendo ser positivo ou negativo. Uma 
condição suficiente para que $\mathrm{A}_{1}$ seja negativo é que $\left(l_{2}^{2}-2 l_{1} c_{1}\right)<0$, ou seja, que:

$$
c_{1}>\frac{l_{2}^{2}}{2 l_{1}}
$$

Dadas essas condições, chegamos às seguintes conclusões a respeito do comportamento do banco quanto à fixação da taxa de juros dos depósitos a vista:

$$
\begin{gathered}
\frac{\partial r_{D}}{\partial E_{L}^{*}}=\frac{A_{1}}{A_{0}}<0 \\
\frac{\partial r_{D}}{\partial r_{W}}=\frac{A_{2}}{A_{0}}>0 \\
\frac{\partial r_{D}}{\partial s_{i}}=-\frac{A_{3}}{A_{0}}<0 \\
\frac{\partial r_{D}}{\partial r}=\frac{A_{4}}{A_{0}}>0
\end{gathered}
$$

Com base no sistema (3la)-(3ld) podemos observar que:

i. Um aumento da taxa esperada de retorno dos empréstimos leva o banco a reduzir a taxa de juros dos depósitos a vista.

ii. Um aumento da taxa mínima de retorno sobre o capital próprio faz com que o banco aumente a taxa de juros dos depósitos a vista.

iii. Um aumento da participação do banco no ativo total do sistema bancário produz uma redução da taxa de juros paga pelo mesmo sobre o volume de depósitos a vista.

iv. Um aumento da taxa de juros das obrigações do governo faz com que o banco aumente a taxa de juros dos depósitos a vista. 
Para fechar o modelo temos que expressar o volume ótimo de crédito bancário e o spread ótimo como uma função dos parâmetros, ou seja, a taxa mínima de retorno sobre o capital próprio, o grau de concentração do setor bancário - medido por $\mathrm{s}_{\mathrm{i}}$ - e a taxa de juros das obrigações do governo. Para tanto, iremos inicialmente escrever as equações $(20),(22),(23)$ e (26) na forma implícita:

$$
\begin{array}{ll}
L=L\left(E_{L}^{*}, r_{D}, s_{i}, r_{w}, r\right) & ; L_{1}>0, L_{2}<0, L_{3}<0, L_{4}<>0, L_{5}=0 \\
R=R\left(E_{L}^{*}, r_{D}, s_{i}, r_{w}, r\right) & ; R_{1}>0, R_{2}<>0, R_{3}<0, R_{4}=0, R_{5}>0 \\
r_{L}=r_{L}\left(\alpha_{k}, r\right) & ; r_{L 1}<0, r_{L 2}=0 \\
r_{D}=r_{D}\left(E_{L}^{*}, s_{i}, r_{w}, r\right) & ; r_{D 1}<0, r_{D 2}<0, r_{D 3}>0, r_{D 4}>0
\end{array}
$$

Observa-se na equação (32a) que a oferta de crédito bancário é uma função da taxa de juros dos depósitos a vista, que, por sua vez, é uma função comportamental apresentada pela equação (32d). Sendo assim, temos que substituir (32d) em (32a) para podermos chegar ao formato final da função de oferta de crédito bancário, isto é, à função que relaciona o volume de crédito ofertado pelo banco com os valores das variáveis exógenas do modelo. Para tanto, iremos inicialmente calcular o diferencial total das equações (32a) e $(32 \mathrm{~d})$ :

$$
\begin{aligned}
& d L=\frac{\partial L}{\partial E_{L}^{*}} d L+\frac{\partial L}{\partial r_{D}} d r_{D}+\frac{\partial L}{\partial s_{i}} d s_{i}+\frac{\partial L}{\partial r_{w}} d r_{w} \\
& d r_{D}=\frac{\partial r_{D}}{\partial E_{L}^{*}} d E_{L}^{*}+\frac{\partial r_{D}}{\partial r_{w}} d r_{w}+\frac{\partial r_{D}}{\partial s_{i}} d s_{i}+\frac{\partial r_{D}}{\partial r} d r
\end{aligned}
$$

Substituindo (33b) em (33a), temos que:

$$
d L=\left\{\frac{\partial L}{\partial E_{L}^{*}}+\frac{\partial L}{\partial r_{D}} \frac{\partial r_{D}}{\partial E_{L}^{*}}\right\} d E_{L}^{*}+\left\{\frac{\partial L}{\partial r_{D}} \frac{\partial r_{D}}{\partial s_{i}}+\frac{\partial L}{\partial s_{i}}\right\} d s_{i}+\left\{\frac{\partial L}{\partial r_{D}} \frac{\partial r_{D}}{\partial r_{w}}+\frac{\partial L}{\partial r_{w}}\right\} d r_{w}+\left\{\frac{\partial L}{\partial r_{D}} \frac{\partial r_{D}}{\partial r}\right\} d r
$$


De (34), sabemos que:

$$
\frac{d L}{d r}=\frac{\partial L}{\partial r_{D}} \frac{\partial r_{D}}{\partial r}<0
$$

Com base em (35a) podemos constatar que um aumento da taxa de juros das obrigações do governo irá resultar numa redução do crédito bancário. Isso ocorre porque um aumento da rentabilidade dos títulos do governo irá levar o banco a aumentar a taxa de juros sobre os depósitos a vista. Esse aumento da taxa de juros dos depósitos irá estimular os agentes econômicos a aumentar o volume de depósitos no banco em consideração, resultando num aumento do prêmio de liquidez e da taxa própria de juros dos ativos defensivos. Em face desse aumento da taxa própria de juros, o banco irá aumentar a sua posição defensiva líquida e, dado o montante de seu passivo, reduzir o volume oferecido de crédito. ${ }^{7}$

De forma análoga, podemos calcular o efeito de um aumento do grau de concentração do setor bancário sobre o volume de crédito com base na seguinte expressão:

$$
\frac{d L}{d s_{i}}=\frac{\partial L}{\partial r_{D}} \frac{\partial r_{D}}{\partial s_{i}}+\frac{\partial L}{\partial s_{i}}
$$

7 Aqui cabe um esclarecimento adicional. O crescimento do volume de depósitos decorrente de um aumento da taxa de juros dos depósitos resulta, no caso em consideração, de um aumento prévio da taxa de retorno das obrigações do governo. Dessa forma, o aumento dos depósitos estará associado a uma redução do volume de empréstimos bancários devido à substituição de empréstimos por obrigações do governo no ativo do banco. Isso porque o aumento da taxa de retorno dos títulos do governo torna os mesmos mais atrativos para o banco relativamente às operações de crédito. Sendo assim, ainda que o aumento do volume de depósitos permitisse um aumento do volume de empréstimos devido ao "maior lastro" oferecido pelos primeiros, a racionalidade econômica impõe a substituição de crédito por títulos do governo no portfólio do banco. 
O primeiro termo de (35b) é positivo (produto de dois termos negativos), mas o segundo termo é negativo. Sendo assim, o sinal de (35b) é ambíguo. O efeito de um aumento do grau de concentração sobre o crédito bancário depende da magnitude do efeito de um aumento do grau de concentração sobre a taxa de juros dos depósitos e da sensibilidade do crédito bancário a uma variação de $r_{d}$. Se os depósitos a vista forem pouco sensíveis às variações do grau de concentração, ou se o crédito bancário for pouco sensível a uma variação da taxa de juros dos depósitos, então (35b) será negativo, isto é, um aumento do grau de concentração irá levar o banco a reduzir o volume de crédito. Mas se isso não acontecer, então um aumento do grau de concentração pode produzir um aumento do crédito bancário.

Essa ambigüidade pode ser explicada pelo efeito do grau de concentração sobre o volume de depósitos a vista e sobre o prêmio de liquidez dos ativos defensivos. Com base na "função de retenção de depósitos" sabemos que um aumento do grau de concentração irá, dada a taxa de juros dos depósitos a vista $\left(\mathrm{r}_{\mathrm{d}}{ }^{0}\right.$ na Figura 3 ), produzir um aumento do volume de depósitos no banco. Esse aumento dos depósitos gera um aumento do prêmio de liquidez dos ativos defensivos, estimulando o banco a aumentar a sua posição defensiva e, dessa forma, a reduzir o volume ofertado de crédito.

No entanto, o "deslocamento para baixo" da função de retenção de depósitos (Figura 3), devido à maior concentração do setor bancário, permite ao banco financiar o mesmo volume de ativos, pagando um preço mais baixo pelo capital de terceiros, ou seja, pelos depósitos a vista. Sendo assim, o banco pode reduzir a taxa de juros paga sobre os depósitos a vista. Essa redução gera uma diminuição do volume de depósitos a vista (um deslocamento ao longo da função de retenção de depósitos), o que reduz o prêmio de liquidez dos ativos defensivos e, conseqüentemente, uma redução da posição defensiva líquida do banco. Nesse contexto, o banco irá aumentar o volume oferecido de crédito. 
FIGURA 3

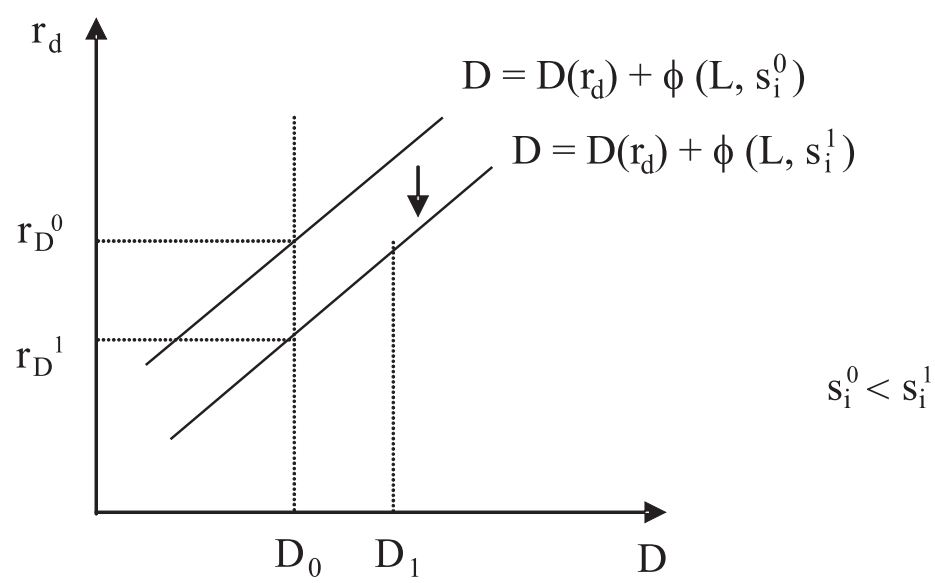

O spread bancário ótimo é igual à diferença entre $r_{L}^{*} e r_{D}^{*}$. Com base em (32c) (e 32d), o spread ótimo $\left(s^{*}\right)$ é dado por:

$$
s^{*}=r_{L}\left(\alpha_{k}\right)-r_{D}\left(E_{L}^{*}, r_{w}, s_{i}, r\right)
$$

Nesse contexto, podemos observar que um aumento do grau de concentração do setor bancário irá produzir um aumento do spread bancário, pois irá induzir o banco a reduzir a taxa de juros paga sobre os depósitos a vista. Isso é possível porque o "deslocamento para baixo" da função de retenção de depósitos permite ao banco captar o mesmo volume de depósitos, pagando um preço mais baixo pelos recursos de terceiros.

Por outro lado, podemos constatar que um aumento da taxa de juros dos títulos do governo - a “taxa básica de juros" - irá reduzir o spread bancário, na medida em que leva o banco a aumentar a taxa de juros paga sobre os depósitos a vista. Isso ocorre porque o aumento da taxa básica de juros aumenta a taxa própria de juros dos ativos defensivos e a posição líquida defensiva do banco. Para poder aumentar a sua posição defensiva líquida, o banco precisa aumentar o volume de recursos disponíveis para financiar a aquisição de ativos. Para fazê-lo, ele tem que aumentar a taxa de juros sobre os depósitos a vista, de forma a captar um volume maior de depósitos. 


\section{CONCLUSÃO}

Ao longo do presente artigo foi apresentado um modelo geral de firma bancária, incorporando à teoria pós-keynesiana da preferência pela liquidez dos bancos a hipótese Stiglitz-Weiss de que a taxa de inadimplência é uma função crescente da taxa de juros dos empréstimos bancários e a função de retenção de depósitos de Tobin.

Nesse contexto, demonstramos que para uma certa constelação de valores dos parâmetros das funções comportamentais (em particular, uma baixa sensibilidade da demanda de depósitos a vista a variações da taxa de juros), um aumento do grau de concentração do setor bancário, medido pela participação da firma bancária nos ativos totais do setor em consideração, irá resultar num aumento do spread entre a taxa de juros dos empréstimos e a taxa de remuneração dos depósitos a vista. Isso ocorre porque um aumento do grau de concentração permite ao banco captar o mesmo volume de depósitos a vista, pagando um preço menor por essa classe de recursos. A taxa de juros dos empréstimos não é, contudo, afetada por variações no grau de concentração do setor bancário, dependendo unicamente de variáveis relacionadas ao nível de "fragilidade financeira" das empresas como, por exemplo, o grau de endividamento e o prazo médio de vencimento dessas dívidas com os credores.

Um outro resultado importante refere-se ao efeito de variações da taxa básica de juros sobre o volume ofertado de crédito bancário. Com efeito, demonstramos que um aumento da taxa básica de juros irá levar o banco a reduzir o volume de crédito oferecido às empresas, aumentando, dessa forma, o nível de racionamento de crédito. Isso ocorre porque um aumento da taxa básica de juros irá aumentar a rentabilidade total dos ativos defensivos - a sua taxa própria de juros -, estimulando os bancos a aumentar a sua posição defensiva líquida. Dado o volume de capital de terceiros, ou seja, o volume de depósitos a vista, um aumento da posição defensiva líquida do banco só será possível mediante uma redução da oferta de crédito bancário.

Entretanto, as variações na taxa básica de juros não têm nenhum impacto sobre o "preço do crédito", ou seja, sobre a taxa de juros dos empréstimos. 
Como corolário desse resultado, segue-se que a política monetária só pode afetar o nível de atividade econômica por intermédio do assim chamado "canal do crédito", ou seja, por meio de variações do volume de crédito existente na economia.

Uma última conclusão importante é que, ao contrário do que seria de se esperar com base no senso comum, um aumento da taxa básica de juros produz uma redução do spread bancário. Isso ocorre porque um aumento da taxa de juros dos títulos do governo irá induzir o banco a aumentar a sua posição defensiva líquida. Para tanto, ele terá que aumentar o volume do capital de terceiros no seu balanço, de forma a obter mais recursos para financiar a aquisição de ativos defensivos. A única forma de fazê-lo é por intermédio de um aumento da taxa de juros paga sobre os depósitos a vista, o que irá induzir os agentes do setor não bancário a substituir papel-moeda por depósitos a vista, aumentando, assim, o volume de depósitos no banco.

\section{REFERÊNCIAS BIBLIOGRÁFICAS}

BALTENSPERGER, E. Alternative approaches to the theory of the banking firm. Journal of Monetary Economics, 6, 1980.

BERNANKE, B. S. Credit in the macroeconomy. Federal Reserve Bank of New York Quarterly Review, v. 18, n.1, 1993.

BERNANKE, B. S; BLINDER, A. S. Credit, money and aggregate demand. American Economic Review, v. 78, n. 2, 1988.

BERNANKE, B. S; GERTLER, M. Inside the black box: the credit channel of monetary policy transmission. Journal of Economic Perspectives, v. 9, n. $4,1995$.

CARVALHO, F. C. Mr. Keynes and the post Keynesians. Edward Elgar: Alderhot, 1992.

. On bank's liquidity preference. Papers and Proceedings Fifht International Workshop in Post Keynesian Economics, Knoxville, 1998.

CECCHETTI, S. G. Distinguishing theories of the monetary transmission mechanism. Federal Reserve of St. Louis Review, v. 77, n. 3, 1995.

DE PAULA, L. F. A teoria da firma bancária. In: LIMA, G. T. et alii. Macroeconomia moderna: Keynes e a economia contemporânea. Rio de Janeiro: Campus, 1999. 
DYMSKI, G. A Keynesian theory of banking behavior. Journal of Post Keynesian Economics, v. X, n. 4, 1989.

. The bank merger wave. Nova Iorque: M. E Sharpe. 1999.

DREIZZEN, J. O conceito de fragilidade financeira num contexto inflacionário. Prêmio BNDES de Economia, 1985.

FREIXAS, X.; ROCHET, J-C. Economía bancaria. Barcelona: Antoní Bosch, 1997.

GERTLER, M. Financial structure and aggregate activity: an overview. Journal of Money, Credit and Banking, v. 20, n. 3, 1997, Parte 2.

KEYNES, J. M. The general theory of employment, interest and money. Londres: MacMillan, 1936.

KLEIN, M. A theory of the banking firm. Journal of Money, Credit and Banking, Maio, 1971.

MINSKY, H. P. John Maynard Keynes. Nova Iorque: Columbia University Press, 1975. . Can "it” happen aggain? Nova Iorque: M. E. Sharpe, 1982.

MOORE, B. Horizontalists and verticalists. Cambridge: Cambridge University Press, 1988.

SANTOMERO, A. Modelling the banking firm. Journal of Money, Credit and Banking, v. 16, n. 4, 1984.

STIGLITZ, J; WEISS, A. Credit rationing in markets with imperfect information. American Economic Review, 71, 1981.

STIGLITZ, J; GREENWALD, B. Towards a new paradigm in monetary economics. Cambridge: Cambridge University Press, 2003.

TOBIN, J. Money, credit and capital. Nova Iorque: McGraw-Hill, 1998.

WALSH, C. E. Monetary theory and policy. Cambridge (Mass.): MIT Press, 2001.

\footnotetext{
Artigo apresentado no VIII Encontro da Sociedade Brasileira de Economia Política, realizado no período de 17 a 20 de junho de 2003 em Florianópolis.

O autor agradece aos comentários de José Gabriel Porcile Meirelles, Ramón Garcia Fernandez e de um parecerista anônimo da Estudos Econômicos. Eventuais falhas são, no entanto, de minha inteira responsabilidade.

E-mail: joreiro@sociais.ufpr.br. Web-page: www.joseluisoreiro.ecn.br.

(Recebido em julho de 2003. Aceito para publicação em maio de 2004).
} 